\title{
Combining patterned membrane filtration and flocculation for economical microalgae harvesting
}

\author{
Zhenyu Zhao $^{a}$, Koenraad Muylaert ${ }^{b}$, Ivo F.J. Vankelecom ${ }^{\mathrm{a}, *}$ \\ ${ }^{a}$ Membrane Technology Group (MTG), Division CMACS, Faculty of Bio-Science Engineering, KU Leuven, Celestijnenlaan 200F, PO Box 2454, 3001 Leuven, \\ Belgium \\ ${ }^{b}$ Lab Aquatic Biology, Microbial en Molecular Systems, KU Leuven KULAK, E. Sabbelaan 53, B-8500 Kortrijk, Belgium
}

\section{A R T I C L E I N F O}

Article history:

Received 13 January 2021

Revised 16 April 2021

Accepted 19 April 2021

Available online 22 April 2021

Keywords:

Flocculation

Patterned membranes

Economic analysis

Microalgae harvesting

Membrane filtration

Phase inversion

\begin{abstract}
A B S T R A C T
Membranes have a lot of potential for harvesting microalgae, but mainly membrane fouling and high harvesting costs linked to low fluxes are hampering their breakthrough. Patterned membranes can reduce fouling by enchancing local turbulences close to the membrane surface on one hand, and by increasing the active area per $\mathrm{m}^{2}$ of installed membrane on the other. Flocculation can further increase membrane permeance by increasing microalgal partical size and reducing the fraction of free organic matter in the feed. In current study, the effect of polyethylene glycol (PEG) in the casting solution of patterned polysulfone membranes was investigated to better tune the performance of the patterned membranes, together with the effects of cross-flow velocity and chitosan dosage on membrane fouling. The energy consumption and total harvesting cost, extrapolated to a full-scale microalgal harvesting, were then estimated. The patterned membrane prepared with a 28w\% PEG concentration showed the highest clean water permeance $\left(900 \pm 22 \mathrm{~L} / \mathrm{m}^{2} \mathrm{~h}\right.$ bar) and membrane permeance in a microalgal suspension $\left(590 \pm 17 \mathrm{~L} / \mathrm{m}^{2} \mathrm{~h}\right.$ bar). Patterned membranes showed a lower filtration resistance (15\% permeance decline at the end of filtration) than flat membranes $(72 \%)$ at a cross-flow velocity of $0.0025 \mathrm{~m} / \mathrm{s}$. Increasing cross-flow velocity could increase membrane permeance in most cases. The highest stable membrane permeance ( $110 \pm 17 \mathrm{~L} / \mathrm{m}^{2} \mathrm{~h}$ bar) and the lowest filtration resistance were achieved when combining patterned membrane filtration with flocculation at optimized chitosan dosage. A very low energy consumption $(0.28 \mathrm{kWh} / \mathrm{kg})$ and harvesting cost $(0.16 € / \mathrm{kg})$ were achieved under these conditions.
\end{abstract}

\section{Introduction}

Microalgae are nowadays cultivated for high value-added compounds production, e.g. nutraceuticals, cosmetics and pharmaceuticals (Chen et al., 2020). However, large-scale industrial production of microalgal biomass is restricted by the high water requirements, which can be overcome by recycling the culture medium or using wastewater. Another paramount disadvantage is the highenergy requirement for microalgae harvesting, due to the small size of microalgae and their growth in strongly diluted conditions (Zhao et al., 2020a).

Centrifugation is currently the most often used method for microalgae harvesting with close to $100 \%$ harvesting efficiency, but also with considerable energy input (Zhao et al., 2020a). Moreover,

\footnotetext{
* Corresponding author.

E-mail address: ivo.vankelecom@kuleuven.be (I.F.J. Vankelecom).
}

an even higher centrifugation speed is required when harvesting microalgae with smaller cell size and lower concentration, resulting in microalgal cell rupture and waste of microalgal inner content (Zhao et al., 2020c).

Flocculation followed by sedimentation or flotation has been considered as an economic and easy way. The main mechanisms for flocculation are charge neutralization, bridging and sweeping (Vandamme et al., 2012a). However, the harvesting efficiency by flocculation hardly ever reaches $100 \%$, especially for marine microalgae, due to the coiling of polymers in high-salinity microalgal culture media (Vandamme et al., 2013). In addition, the relatively high dosage of flocculants and long sedimentation times influence the microalgal purity and processing time, respectively. $\mathrm{pH}$ induced flocculation (i.e. without adding flocculants) always takes places at a relatively high $\mathrm{pH}$ level, seriously decreasing the microalgal quality (Wan et al., 2015). Low harvesting efficiency also hampers the re-use of culture medium, leading to excessive use of water. 
Membrane separation allows to separate microalgal cells from culture media with $100 \%$ harvesting efficiency at lower energy input than centrifugation (Zhao et al., 2020a). However, fouling caused by microalgae themselves and extracellular organic matter (EOM) seriously impacts membrane flux and long-term use (Zhao et al., 2021). Several approaches, like introducing turbulence and surface modification, have been used to alleviate fouling on the membrane surface (Bilad et al., 2014, 2013). Recently, membrane surface patterning has gained a lot of attention, because of the extended surface area and the unique flow behavior near the membrane surface. Patterned membranes have been used for microalgae harvesting and showed significantly higher membrane fluxes and critical pressures (CPs) in cross-flow systems than corresponding flat membranes (Zhao et al., 2020a).

Flocculation combined membrane filtration (Discart et al., 2015: Zhao et al., 2020b) can cope with the disadvantage of flocculation (i.e. relatively low harvesting efficiency and long sedimentation time), while flocculation can facilitate membrane separation by increasing particle size (i.e. forming bigger flocs) and agglomerating EOMs (Lu et al., 2020; Vandamme et al., 2012b). By combining membrane filtration with flocculation, membranes with larger pore size can thus be used due to the increased particle size, and less microalgal cells may attach on the membrane surface because of reduced surface charge and decreased EOM contents (Discart et al., 2015). This should enhance membrane flux and therefore decrease energy demand. Chitosan flocculation-assisted polytetrafluoroethylene (PTFE) membrane filtration for Chlorella vulgaris (C. vulgaris) harvesting showed that filtration performance was significantly improved with $100 \%$ harvesting efficiency at different microalgal growth stages (Chang and Lee, 2012). Chitosan flocculation combined with microfiltration proved highly efficient for C. sorokiniana harvesting, achieving 20-50 fold concentration (Xu et al., 2013). Besides, membrane fluxes and harvesting efficiencies increased with increasing chitosan dosage for C. vulgaris and Dictyosphaerium sp., indicating that the synergy between membrane filtration and flocculation not only exists under optimal chitosan condition, but also under sub-optimal condition (Lee et al., 2012a; b; Zhao et al., 2020b). Patterned membranes have not been used yet in flocculation-assisted filtration. It is now hypothesized that membrane performance can also be intensively improved by combining patterned membrane filtration with flocculation, even under low cross-flow velocity, hence decreasing energy input and total harvesting cost. Polyvinylidene fluoride (PVDF) and polyvinyl chloride (PVC) are the most commonly used membrane materials for microalgae harvesting, and the energy consumption is normally in a very broad range of $0.17-2 \mathrm{kWh} / \mathrm{m}^{3}$ (Bilad et al., 2015; Mo et al., 2015).

In the current study, chitosan was used as flocculant, and was combined with patterned membrane filtration in a cross-flow system. Based on a previous study (Zhao et al., 2020a), the polysulfone (PSf) membrane pattern structure and performance were investigated to further explore the beneficial addition of polyethylene glycol (PEG) concentration to the casting solution to optimize membrane structure. A recently developed process involving modified phase inversion by spraying of the non-solvent on the cast polymer film, was used to prepare membranes with patterns at the active side of the membrane (Ilyas et al., 2020; Marbelia et al., 2020). The membrane performance under optimal/sub-optimal dosages of flocculant, and varying cross-flow velocities was determined to investigate the synergy between this advanced type of membrane filtration and flocculation. Finally, the main criteria (energy consumption, capital cost, labor cost and operational cost) were calculated to quantitatively estimate the harvesting cost at industrial scale. This study thus not only optimizes the patterned membranes, but also offers a feasible way for harvesting microalgae at low cost and reduced energy input.

\section{Materials and methods}

\subsection{Cultivation of microalgae}

Dictyosphaerium sp. (Zhao et al., 2020d) was selected as model microalgal strain due to its high lipid content, and has the potential of biofuel production. Microalgae were cultivated in a 30L plexiglas column photobioreactor with 25-L of BG-11 medium (Zhao et al., 2016). The cultivation was carried out under continuous aeration of $15 \mathrm{~L} / \mathrm{min}$ with constant illumination of 100 $\mu \mathrm{mol}$ photons $\mathrm{m}^{-2} \mathrm{~s}^{-1}$ for 7 days (stationary phase). The final dry weight of Dictyosphaerium sp. in the culture medium was $0.81 \pm 0.09 \mathrm{~g} / \mathrm{L}$.

\subsection{Membrane preparation}

The patterned membranes were prepared using a modified spraying method, as described elsewhere (Marbelia et al., 2020). The casting machine (Braive Instruments, Belgium) contains an extra sprayer providing deionized water as non-solvent, which allows water to be simultaneously sprayed with the casting knife to immediately maintain patterns on the freshly shaped membrane surface (Hołda et al., 2013; Zhao et al., 2020a). The wavelike patterned knives were 3D printed using VeroWhitePlusTM RGD835 (Stratasys Ltd, Eden Prairie, USA) as resin material and the schematic diagram of the wave-like patterned knife is shown in Fig. S1. PSF (UD1700, Solvay, Belgium) with a concentration of $18 \mathrm{w} \%$, was dissolved in N-methyl-2-pyrrolidone (NMP, 99w\%, Acros organics, Belgium) using PEG (Mw 1000 Da, Fluka, Belgium) as pore-forming agent. To further increase membrane permeance, PEG concentrations were set from $25 \mathrm{w} \%$ to $37 \mathrm{w} \%$ based on a previous study (Zhao et al., 2020a). After stirring at $80 \mathrm{rpm}$ at $60{ }^{\circ} \mathrm{C}$ for $24 \mathrm{~h}$ and degassing overnight, the casting solutions were cast on a smooth glass plate at a speed of $2.25 \mathrm{~cm} / \mathrm{s}$ using a wave-like patterned knife $(d=150 \mu \mathrm{m}, h=900 \mu \mathrm{m})$ with a wet thickness of $200 \mu \mathrm{m}$ measured from the plate to the bottom of the knife patterns (Fig. S1). The cast film was then immediately immersed into deionized water $\left(2{ }^{\circ} \mathrm{C}\right)$ to complete the phase inversion. A reference membrane (i.e. flat membrane without surface pattern) was made using a conventional flat casting knife with the same wet thickness and was directly immersed into the coagulation bath without spraying.

\subsection{Membrane characterization}

The surfaces and cross-sections of the membranes were observed using scanning electron microscopy (SEM, JEOL JFC-1300, Tokyo, Japan). The actual pattern height and inter-pattern distance were also determined using SEM. The surface chemical property was characterized using Attenuated Total Reflectance FourierTransform Infrared Spectroscopy (ATR-FTIR, Bruker Alpha, Germany) with a $4000-400 \mathrm{~cm}^{-1}$ spectral scanning range.

\subsection{Feed preparation}

Three different kinds of feeds were used for filtration, which were untreated microalgal suspension (UMS), flocculated microalgal suspensions under optimal (FOS) and sub-optimal (FSS) flocculant concentration, respectively. For flocculated microalgal suspensions, chitosan (Polysciences, Belgium) was used as flocculant with a $5 \mathrm{~g} / \mathrm{L}$ stock solution prepared in $0.1 \mathrm{~mol} / \mathrm{L} \mathrm{HCl}$ (Sigma-Aldrich, Belgium). $\mathrm{HCl}(0.5 \mathrm{~mol} / \mathrm{L})$ and $\mathrm{NaOH}$ (ACROS, Belgium) $(0.5 \mathrm{~mol} / \mathrm{L})$ stock solutions were used for $\mathrm{pH}$ adjustment. The flocculation was achieved as previously described (Zhao et al., 2020b). Briefly, a lab-scale jar with $1 \mathrm{~L}$ untreated microalgal suspension was 
used to prepare flocculated feeds. Untreated microalgal suspension with initial $\mathrm{pH}$ around 9 was adjusted to 6 (Vandamme et al., 2012a). For optimal and sub-optimal flocculant concentration, microalgal suspensions were first dosed with 5 and $2 \mathrm{mg} / \mathrm{L}$ chitosan (Zhao et al., 2020b), respectively, and then stirred vigorously (350 rpm) for $10 \mathrm{~min}$. After that, the suspensions were stirred gently at $50 \mathrm{rpm}$ for $20 \mathrm{~min}$ to form flocs. The suspensions were allowed to settle for $30 \mathrm{~min}$ before cross-flow filtration. The entire solution with supernatant and flocs was used as feed, and the feed needs to be freshly prepared before each experiment.

\subsection{Filtration experiments}

\subsubsection{Dead-end filtration}

Membrane permeance of each membrane was determined using a high-throughput dead-end filtration system (HTML, Belgium) which contains 8 membrane coupons with a $2.27 \mathrm{~cm}^{2}$ filtration active area each (Ilyas et al., 2020). The average clean water permeance (CWP) was determined by filtering deionized water under constant pressure (1.5 bar). Before determination, the membrane was first stabilized by filtrating deionized water at 1 bar for $10 \mathrm{~min}$ until the CWP leveled off. The permeate was then collected during 10 min of filtration, and the CWP was calculated using Eq. (1). The average membrane permeance in UMS was measured under 1 bar pressure for $30 \mathrm{~min}$, and was also calculated using Eq. (1). Microalgae retention was determined by measuring the optical density (OD) at $680 \mathrm{~nm}$ and calculated according to Eq. (2).

$J=\frac{V}{A \cdot t \cdot T M P}$

$R=\frac{A_{U M B}-A_{p}}{A_{U M B}}$

where $J$ is the membrane permeance $\left(\mathrm{L} / \mathrm{m}^{2} \mathrm{~h}\right.$ bar); $V$ the permeate volume (L); $A$ the membrane active area $\left(\mathrm{m}^{2}\right) ; t$ the filtration time (h); TMP the trans-membrane pressure (bar); $R$ the microalgae retention (\%); $A_{U M S}$ the OD of the feed; $A_{p}$ the OD of the permeate.

\subsubsection{Cross-flow filtration}

The filtration performances of the membranes using three different feeds (UMS, FOS and FSS) were determined in a pressuredriven HT cross-flow filtration system (HTML, Belgium) which contains 4 membrane samples with $10 \mathrm{~cm}^{2}$ filtration active area each. Before harvesting, the membrane was first stabilized by pre-pressurization using deionized water with a maximum pump speed of $0.015 \mathrm{~m} / \mathrm{s}$ at 2 bar until the CWP leveled off. The filtrations were carried out under different cross-flow velocities $(0.0025,0.005,0.01$ and $0.015 \mathrm{~m} / \mathrm{s})$. The patterned membranes were fixed with the surface pattern lines perpendicular to the feed flow direction. The membrane permeances using three feeds were also calculated using Eq. (1).

The CPs under different cross-flow velocities were determined using a stepwise method according to a previous study (Zhao et al., 2020a). The applied initial pressure, step height and step duration were 1 bar, 0.5 bar and $2 \mathrm{~h}$, respectively.

The maximal wall shear rate $\left(\mathrm{s}^{-1}\right)$ on the membrane surface in cross-flow system was calculated following a previous study (Kang et al., 2004), and the equation is shown as follows. The conversion of cross-flow velocity into shear rate is shown in Table S1.

$\tau=\frac{6 Q_{f}}{W_{c} H_{c}^{2}}$

where $Q_{f}$ is volumetric feed flow rate $(\mathrm{mL} / \mathrm{s}) ; W_{c}$ and $H_{c}$ the crossflow channel width and height $(\mathrm{cm})$, respectively.

\subsubsection{Determination of the reversible and irreversible fouling}

The fouling experiments under different cross-flow velocities were performed using the flat and patterned membranes in microalgal suspension at a constant TMP with an intermediate cleaning procedure (i.e. change microalgal suspension to deionized water) according to previous studies (Elcik et al., 2016; Zhang et al., 2019) with some modifications. The reversible fouling can thus be removed through a cleaning procedure. Every filtration run contains 3 continuous cycles, and each cycle consists of 3 steps: (1) filtrations of UMS and flocculated microalgal suspensions for $1.5 \mathrm{~h}$ each of at a constant TMP of 1.5 bar; (2) cleaning of the membrane surface using deionized water for $30 \mathrm{~min}$ at constant TMP of 0.5 bar; and (3) filtration of deionized water at 1.5 bar for $1.5 \mathrm{~h}$ (for determination of reversibility of fouling). The membrane permeances using UMS or flocculated microalgal suspensions as feed at the end of filtration were defined as $J_{x(n)}$ with $\mathrm{n}$ (from 1 to 4) representing the number of cycle. The membrane permeance using deionized water as feed after cleaning at the end of each filtration cycle was defined as $J_{n}$. The membrane permeance can be expressed using Eq. (4). The normalized total fouling (TF), reversible fouling (RF) and irreversible fouling (IF) of each filtration cycle were calculated as follows:

$J_{n}=\frac{\Delta M}{\rho_{P} A t}$

$T F_{n}=\frac{J_{0}-J_{x(n)}}{J_{0}}$

$I F_{n}=\frac{J_{0}-J_{n}}{J_{0}}$

$R F_{n}=T F_{n}-I F_{n}$

where $\Delta M$ is the increase of the permeate $(\mathrm{g}) ; A$ the membrane active area $\left(\mathrm{m}^{2}\right) ; \rho_{P}$ the water density $\left(\mathrm{g} / \mathrm{m}^{3}\right)$; $\mathrm{t}$ the filtration time $(\mathrm{s}) ; J_{0}$ the clean water permeance $(\mathrm{m} / \mathrm{s})$.

\subsection{Economic analysis}

The energy consumption of the pump ( $E p, \mathrm{~kW}$ ) for filtration and feed transfer is calculated according to a previous study (Wang et al., 2019) using Eq. (8).

$E_{p}=\operatorname{r\rho gh} /\left(3.6 \times 10^{6}\right) / \eta_{p}$

where $r$ is the flow rate $\left(\mathrm{m}^{3} / \mathrm{h}\right) ; \mathrm{g}$ the gravity $\left(9.81 \mathrm{~m} / \mathrm{s}^{2}\right) ; \mathrm{h}$ the differential head (30 $\mathrm{m}$ (Wang et al., 2019)); $\eta_{p}$ the pump efficiency (90\% (Wang et al., 2019)).

The energy demand for the flocculation process is mainly linked to the mixing. The energy consumption of stirrer $\left(E_{s}, \mathrm{kWh}\right)$ is based on an industrial liquid mixer (WLDH-15, capacity of 15,000 L, maximum power of $55 \mathrm{~kW}$, Jiangyin Wantong Pharmaceutical and Chemical Machinery Co., Ltd., China).

The energy consumption required for compression of air ( $E_{\text {air }}$, $W$ ) is calculated according to a previous study (Wang et al., 2019) using Eq. (9).

$$
E_{\text {air }}=745.7\left[4075.2 N P_{1} V_{\text {air }} k /(33000(k-1))\right]\left[\left(P_{2} / P_{1}\right)^{(k-1) / N k}-1\right] / \eta_{\text {air }}
$$

where $N$ is the compression stage number ( 1 in this study): $k$ the adiabatic expansion coefficient (1.41); $P_{1}$ the absolute initial atmospheric pressure ( $\mathrm{psi}$ ); $P_{2}$ the absolute final atmospheric pressure (psi); $V_{\text {air }}$ the volume of air under atmospheric pressure $(\mathrm{L} / \mathrm{min})$; $\eta_{a i r}$ the efficiency of air compressor.

$E=\frac{E_{T}}{V_{p} C_{A}}$ 

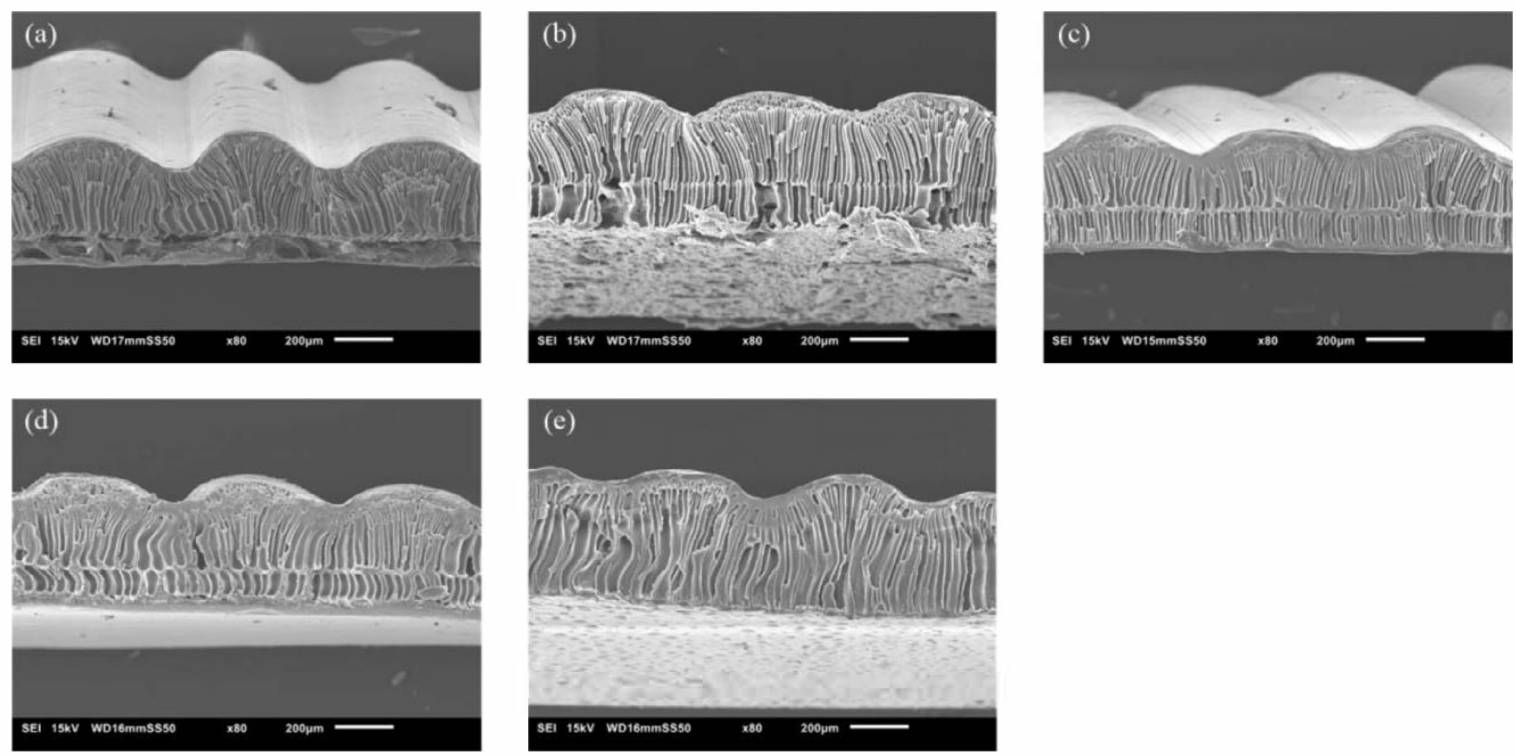

Fig. 1. Cross-sectional images of the patterned membranes prepared from casting solutions containing different PEG concentrations ((a) $25 w \%$, (b) $28 w \%$, (c) $31 w \%$, (d) $34 w \%$ and (e) 37 wo) together with $18 \mathrm{w} \%$ PSf and $1 \mathrm{w} \%$ deionized water in NMP.

where $\mathrm{E}$ is the energy consumption expressed as kWh per dry microalgal mass $(\mathrm{kWh} / \mathrm{kg}) ; E_{T}$ the total energy consumption of crossflow system including pump, stirrer and compressed air (kWh); $V_{p}$ the volume of the permeate $(\mathrm{L}) ; C_{A}$ the microalgal concentration $(\mathrm{kg} / \mathrm{L})$

To estimate the total harvesting cost per dry microalgal biomass, the evaluation was adapted from a full-scale microalgal setup with 60 filtration units of $600 \mathrm{~m}^{2}$ each (Wang et al., 2019). The following rules were taken into consideration to evaluate the energy consumption and total harvesting cost of the cross-flow system:

(a) The calculation was based on the theoretical proportional change of volumetric capacity, and converted to membrane area.

(b) The energy consumption was only related to two peristaltic pumps (one for generating cross flow, and another one for supplying feed) and compressed air.

\subsection{Statistic analysis}

All experiments were carried out in triplicate, and the results were expressed as mean values \pm standard deviation (SD). The significance of the results was analyzed using statistical product and service solutions (SPSS) 17.0 and analysis of variance (ANOVA) with least significant digit (LSD) analysis $(P<0.05)$.

\section{Results and discussion}

\subsection{Influence of PEG addition on membrane characteristics}

To investigate the effect of PEG concentration in the casting solution on the characteristics of the patterned membranes, membranes with different PEG concentrations were prepared at a fixed PSf concentration of $18 \mathrm{w} \%$. Only PEG concentrations above $25 \mathrm{w} \%$ were selected to realize really high porosities (Zhao et al., 2020a). The cross-sections of the patterned membranes are shown in Fig. 1. All PEG-blend membranes possess a remarkable bilayered structure, containing two zones of finger-like macrovoids, in line with a previous study where the maximum content of PEG was $25 w \%$ (Zhao et al., 2020a). The bilayered structure is created

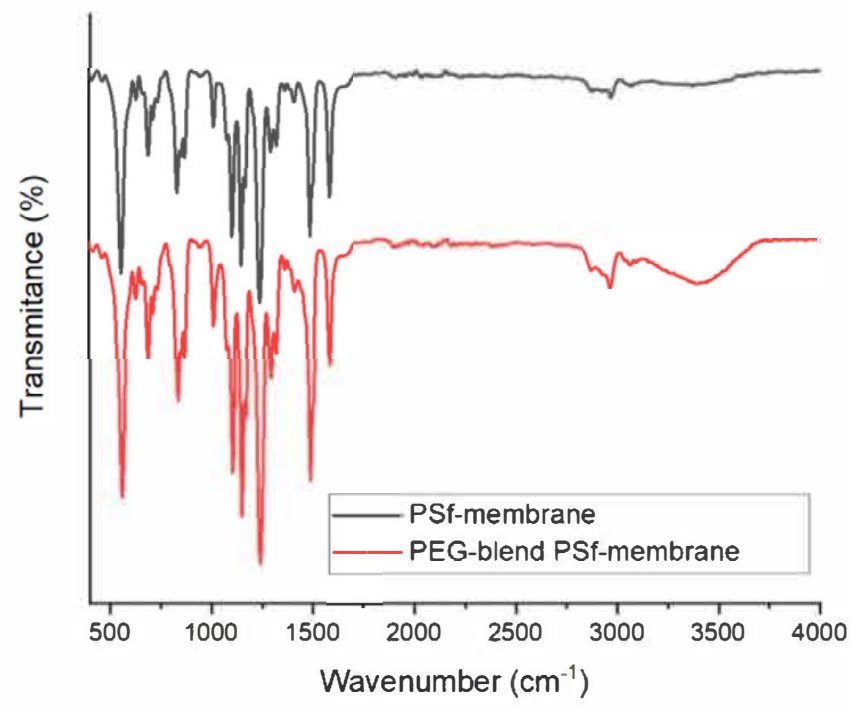

Fig. 2. FTIR spectra of PSf and PEG-blend PSf-membranes.

because the pores are created during two distinct events. A certain volume of non-solvent is first sprayed on top of the cast film. This amount is not sufficient to complete the phase inversion process over the whole cross-section. The bottom part is only finalized later when the film is immersed in the coagulation bath. Water then also penetrates the film from the bottom side and sufficient water is present to complete the whole membrane formation (Hołda and Vankelecom, 2014). The pores are created using phase inversion process. During the phase inversion process, a thermodynamically stable polymer solution is transformed from a liquid into a solid state in a controlled manner. This solidification is preceded by a liguid-liquid demixing. A certain time after initiation of the demixing into a polymer-rich and a polymer-lean phase, the pahse with the highest polymer concentration will start solidifying through processes like gelation, vertrification, or crystallization. The polymer-lean phase will lead to the proes in the solidified material, while the polymer-rich phase will lead to the solid membrane matrix (Hołda and Vankelecom, 2015). 
(a)

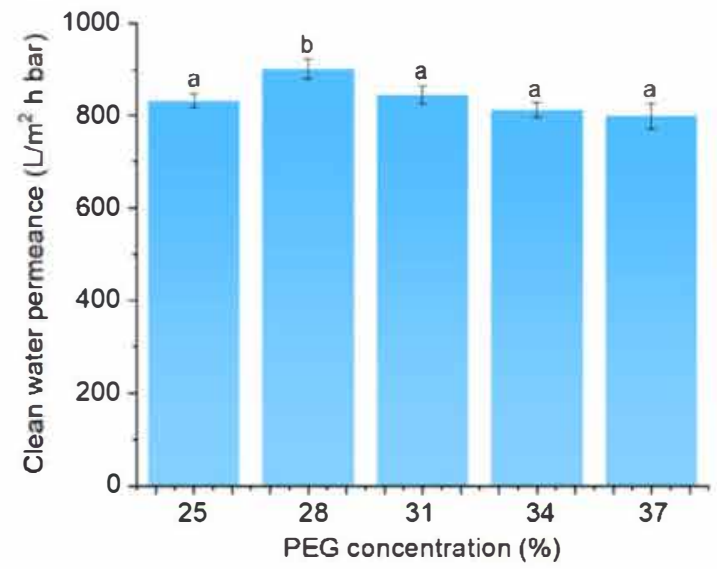

(b)

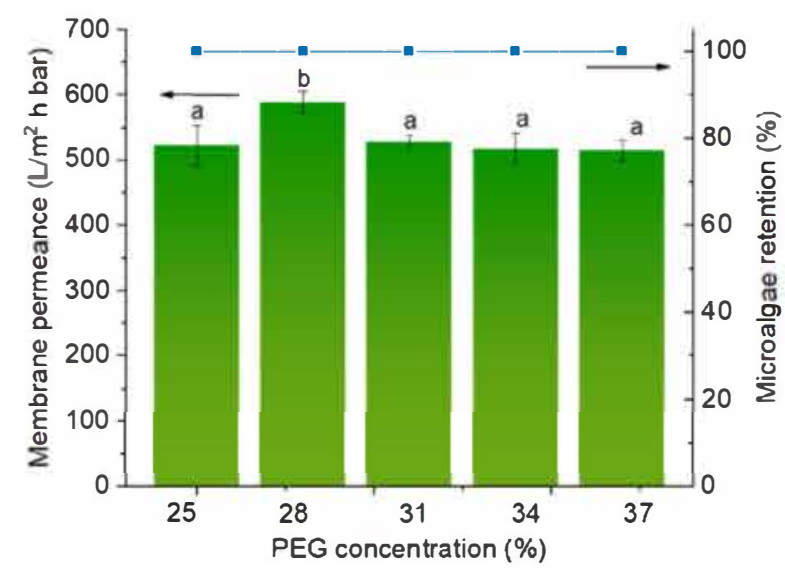

Fig. 3. (a) CWP, (b) membrane permeance (using UMS as feed) and microalgae retention of the patterned membranes prepared from PSf casting solutions containing different PEG concentrations (from $25 w \%$ to 37 w\%). a-b shows the significance; values marked with the different lower case letters are significantly ( $P<0.05$ ) different. Note: the error bars represent the standard deviation.

Comparing the FTIR-spectrum of PSf-membrane, two stronger absorptions (Fig. 2) of PEG-blend PSf-membranes are observed at approximately 1293 and $2960 \mathrm{~cm}^{-1}$, attributed to the $\mathrm{C}-\mathrm{O}-\mathrm{C}$ and $\mathrm{C}-\mathrm{H}$ bonds. When incorporating PEG in the membrane, the absorption rate increased due to the increased $\mathrm{C}-\mathrm{O}-\mathrm{C}$ and $\mathrm{C}-\mathrm{H}$ bonds in PEG, in agreement with a previous study (Nasirian et al., 2019).

The patterned membranes tended to be more water-permeable with increasing PEG concentration until 28w\% (highest CWP of $900 \pm 22 \mathrm{~L} / \mathrm{m}^{2} \mathrm{~h}$ bar) (Fig. 3a). A further increase in PEG concentration led to a decreased CWP. Although no significant difference $(P>0.05)$ was found for patterned membranes prepared with PEG concentrations from $31 \mathrm{w} \%$ to $37 \mathrm{w} \%$, a small decrease was still found. A similar situation was also found when filtering microalgal suspensions (Fig. 3a). For all membranes, the microalgae retention was higher than 99\% (Fig. 3b), proving the usability of these patterned membranes. Just like the CWP, the highest membrane permeance $\left(590 \pm 17 \mathrm{~L} / \mathrm{m}^{2} \mathrm{~h}\right.$ bar) in UMS-filtration was also obtained when using a patterned membrane prepared from a $28 \mathrm{w} \%$ PEG casting solution. In addition, all other trends were also confirmed. Therefore, the optimal PEG concentration was 28\%, above which the retention increase was no longer significant, but the membrane permeance decreased further. A similar result was found in another study where PEG-blend PSf-membranes showed a critical PEG concentration of around $5 \mathrm{w} \%$, above which the rejection increase was not significant, while the membrane permeance decreased (Hołda and Vankelecom, 2014). When excessive PEG was added into casting solution, the viscosity of the casting solution increased, leading to a slower precipitation rate (Hołda and Vankelecom, 2014). A polymer-lean phase is therefore intertwined with a polymer-rich phase, suppressing macrovoids (Ma et al., 2011).

Increasing the PEG concentration leads to more PEG leaching during membrane formation, and makes the casting solution thermodynamically less stable. The latter enhances the demixing process and results in a more porous membrane, thereby increasing the CWP and the UMS permeance (Hołda and Vankelecom, 2014; Ma et al., 2011). However, further increasing the PEG concentration results in a thicker layer above the macrovoids and suppresses macrovoid formation (Fig. 1), leading to a decreased CWP and UMS-permeance (Hołda and Vankelecom, 2014).

Even though previous studies used slightly different suspensions and filtration conditions, the reported membrane permeances for a real microalgal suspension of 133 and $286 \mathrm{~L} / \mathrm{m}^{2} \mathrm{~h}$ bar, obtained by using negatively charged polycarbonate and nylon nanofiber membranes, respectively (Bilad et al., 2018; Huang et al.,
2020). The UMS-permeances above $500 \mathrm{~L} / \mathrm{m}^{2} \mathrm{~h}$ bar in present work clearly prove the advantages of the optimized PEG-blend PSf patterned membranes.

\subsection{Effects of cross-flow velocity and flocculation on $C P$ and membrane permeance}

To investigate the synergy between flocculation and membrane filtration, the microalgal suspension filtration was compared with that of flocculated microalgal suspensions (FOS VS FSS). To clarify the effect of flocculant concentration on membrane filtration performance, FSS and FOS were thus used as feed solutions. Patterned membranes were prepared with fixed PSf and PEG concentrations of $18 \mathrm{w} \%$ and $28 \mathrm{w} \%$, respectively. A flat membrane using the same casting solution and wet casting thickness (but a non-corrugated knife) was prepared as reference by directly immersing the cast film in the coagulation bath (i.e. without spraying). The patterned and flat membranes were potted in a cross-flow filtration system using three different feeds (UMS, FSS and FOS) at different crossflow velocities to determine both the effects of flocculation and cross-flow velocity on membrane filtration performance. To evaluate the anti-fouling capacity, a method was used to determine the $\mathrm{CP}$ by gradually increasing pressure. A more significant fouling occurs as pressure is stepwise increased. A higher CP thus represents a higher anti-fouling capacity (Zhao et al., 2020a). The experimental limit of this pressure was 2.5 bar. The patterned and flat membranes both showed a $\mathrm{CP}>2.5$ bar (Fig. 4) using three different feeds at every cross-flow velocity, thus proving the advantage of using the optimized casting solution.

After 8 h of filtration (Fig. 4), the membrane permeance significantly decreased for both membranes. For flat membranes (Figs. 4a-4c), as expected, the membrane permeance increased with increasing chitosan dosage at the same cross-flow velocity, and it also increased with increasing cross-flow velocity when using the same feed, in line with previous studies (Zhang et al., 2019; Zhao et al., 2020b). Microalgae cells and EOM are the main fouling sources in membrane filtration, forming a cake layer and therefore decreasing membrane permeance and causing serious irreversible fouling (Bilad et al., 2013; Zhao et al., 2020b). The increase in particle size resulting from addition of chitosan creates a more open and dynamic layer on the membrane surface and generates multiple voids for water passage (Figs. 5a-5c) (Blockx et al., 2018; Gonçalves et al., 2017; Zhao et al., 2020b). FOS gives a bigger floc size and lower EOM content(Zhao et al., 2020b), there- 
Flat membranes

(a)

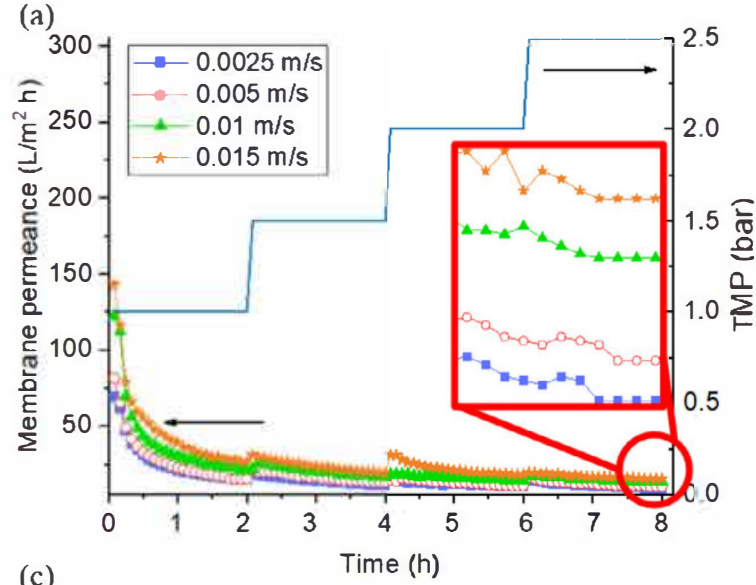

(c)

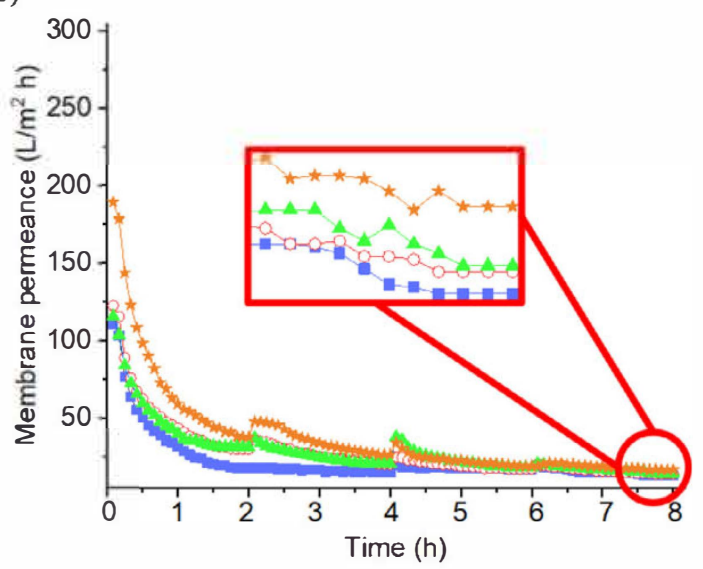

(e)

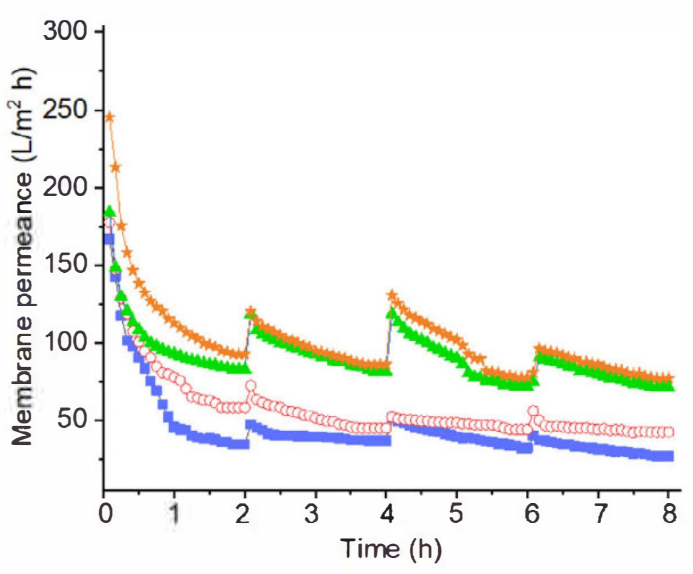

Patterned membranes
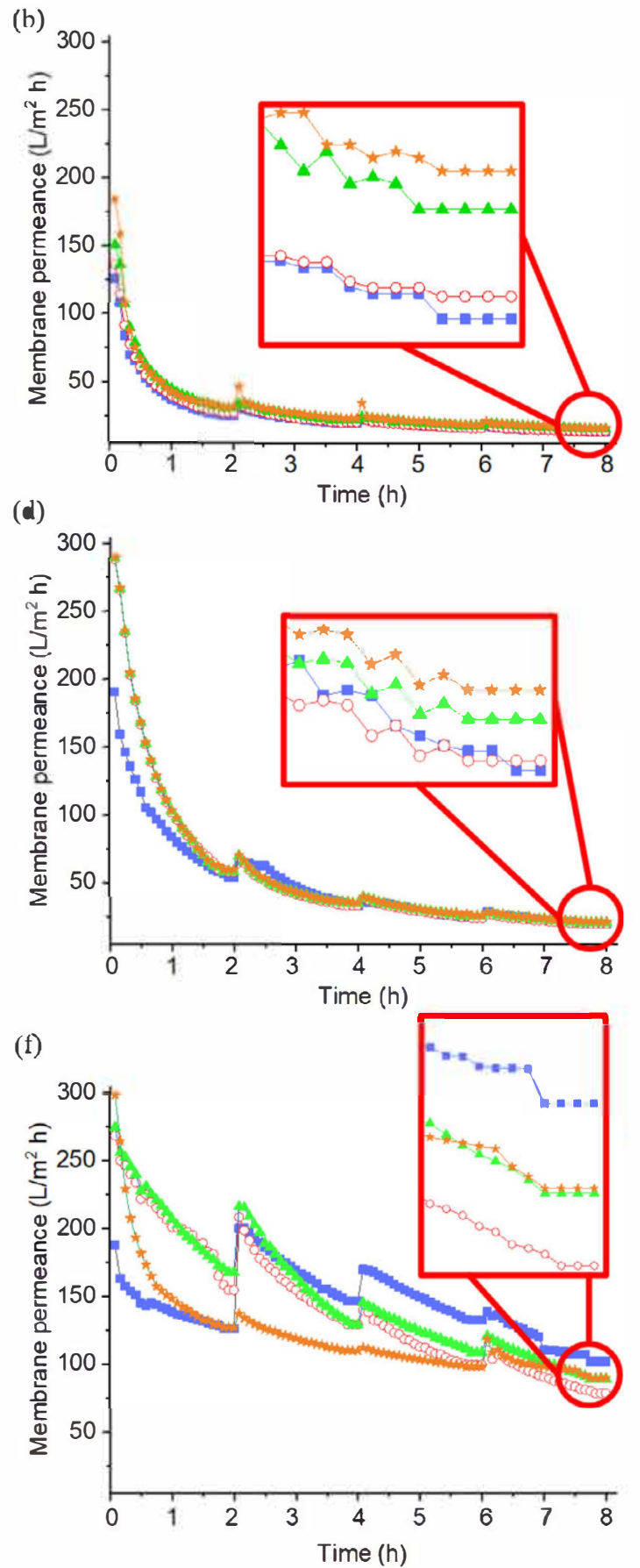

Fig. 4. Microalgal filtrations using the stepwise filtration method using (a and b) UMS, (c and d) FSS and (e and f) FOS as feeds in a cross-flow system.

fore resulting in a higher membrane permeance. Shear-induced filtration can alleviate the cake layer formation on the membrane surface, and higher shear results in a less fouled membrane surface (Zhang et al., 2019). The difference of membrane permeance at different cross-flow velocities increases with increasing flocculant dosage, and a huge improvement is observed when the crossflow velocity reaches $0.01 \mathrm{~m} / \mathrm{s}$ (Fig. 4c), indicating a synergy between flocculation and cross-flow filtration under this condition. Further increase in cross-flow velocity did not give a significant improvement of membrane permeance. This situation is possibly due to the fact that the irreversible fouling formed during the fil- tration process can not be removed at low shear (i.e. at low crossflow velocities), leading to a similar filtration behavior. When increasing the shear to $0.01 \mathrm{~m} / \mathrm{s}$ (corresponding shear rate of 3.75 $\mathrm{s}^{-1}$ ), more fouling is removed, but a further increase in shear did not significantly reduce fouling. The same situation was also found in Isochrysis zangjiangenis separation using a PVC membrane in cross-flow with a rather high velocity of $0.51 \mathrm{~m} / \mathrm{s}$, where a further increase in velocity did not give a significant improvement (Zhang et al., 2019).

For patterned membranes in UMS and FSS (Fig. 5d and e), similar to the situation of the flat membrane, membrane permeances 


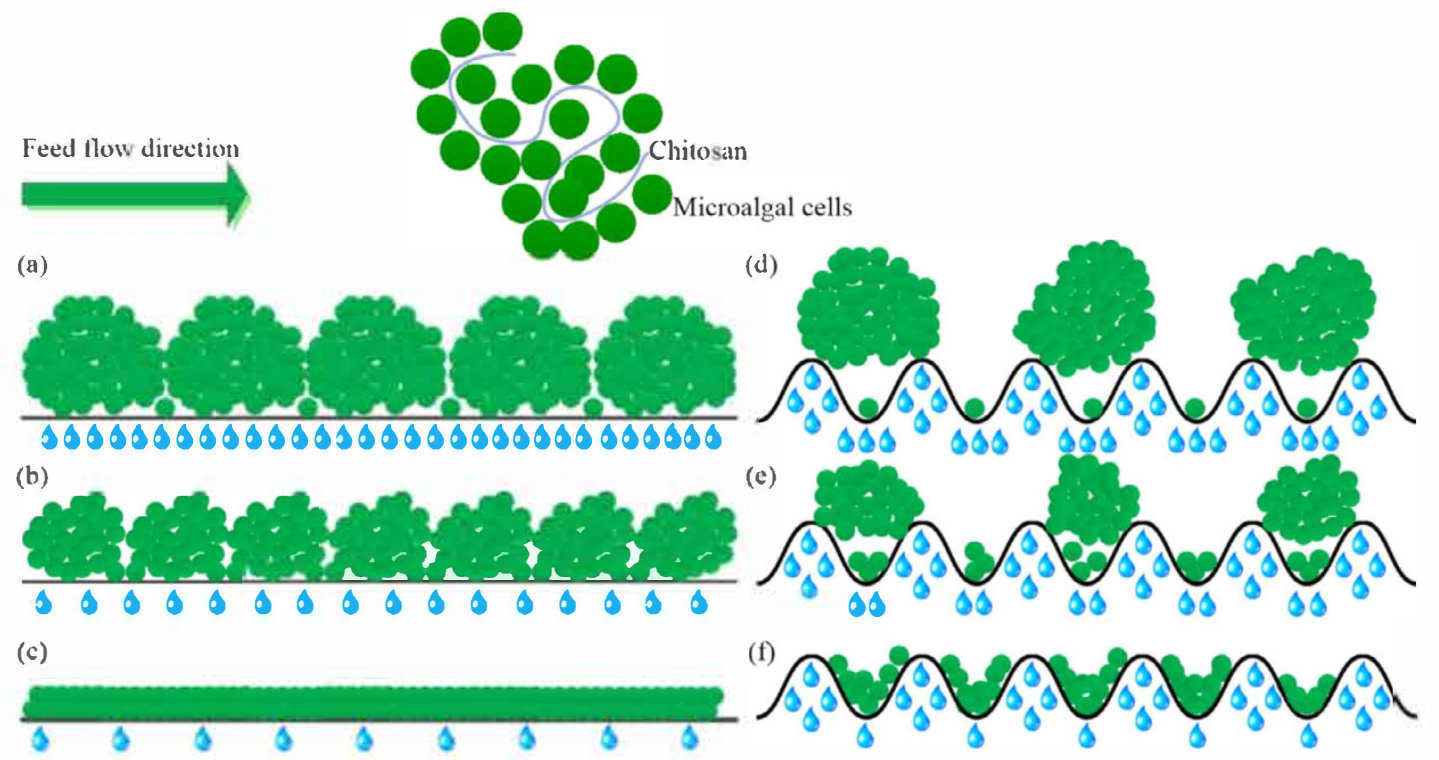

Fig. 5. Schematic of microalgal cell deposition on (a-c) flat membranes and (d-f) patterned membranes using (a and d) FOS, (b and e) FSS and (c and f) UMS as feed in a cross-flow system. The close-up above represents the flocculation mechanism of chitosan.

thus tend to be higher at high velocity and high chitosan dosage. A similar trend was also found in FOS during the first $2 \mathrm{~h}$, where velocities of 0.005 and $0.01 \mathrm{~m} / \mathrm{s}$ gave the highest membrane permeance, followed by velocities of 0.015 and $0.0025 \mathrm{~m} / \mathrm{s}$. An unusual trend was found after that: a velocity of $0.0025 \mathrm{~m} / \mathrm{s}$ showed the highest membrane permeance, while a further increase of velocity lowered the membrane permeance, and velocities of 0.005 and $0.01 \mathrm{~m} / \mathrm{s}$ showed the same filtration performance during the whole filtration process (Fig. 4f). Unlike with the flat membranes, the highest velocity did not give a better filtration performance, indicating that high shear may not favor the flocculation-assisted patterned membrane filtration in a cross-flow system. These phenomena can be explained by the shear dilemma (Zhao et al., 2020a,b) which describes a discrepancy between the high shear required to remove membrane fouling and the rupture of microalgal flocs following such strong movements. When using UMS and FSS as feeds, the small flocs and remaining free cells can still be trapped easily in the valleys (Fig. 5e and f), giving a similar feed condition at every velocity, therefore showing a constant filtration performance compared with the flat membranes. However, when using UMS as feed, the average floc size of Dictyosphaerium sp. flocs is $3.3 \mathrm{~mm}$ (Zhao et al., 2020b), allowing microalgal flocs to be situated above the valleys (the actual inter-pattern distance is $0.4 \pm 0.1 \mathrm{~mm}$ ) (Fig. 5d). Under this condition, less microalgal cells are trapped in the valleys, and the contact between flocs and membrane surface is reduced, giving more area for water passing through. High shear can lower the floc size. In the first $2 \mathrm{~h}$, the big flocs may not be intensively ruptured yet at velocities of 0.005 and $0.01 \mathrm{~m} / \mathrm{s}$ (corresponding shear rates of 1.88 and $3.75 \mathrm{~s}^{-1}$, respectively). After $2 \mathrm{~h}$, the flocs can only remain relatively big at a velocity of $0.0025 \mathrm{~m} / \mathrm{s}$ (corresponding shear rate of $0.94 \mathrm{~s}^{-1}$ ). Due to the reduced EOM (Zhao et al., 2020b), the flocs can be removed easily from the membrane surface at this velocity, therefore resulting in a higher membrane permeance than at other velocities.

Previous studies all showed that membrane permeances in cross-flow systems increase with increasing flow velocities (Balti et al., 2018; Wicaksana et al., 2012; Zhang et al., 2019). However, they also result in a higher energy input. In current study, flocculation and membrane surface pattern alone did help against fouling at high velocity, but when flocculation-assistance was in- troduced and combined with membrane surface patterns, a huge improvement in membrane permeance was realized, even at a very low velocity already, which implies a huge energy saving. Previous study also showed that the microalgal cells maintain their integrity even at enhanced shear rate $\left(1250 \mathrm{~s}^{-1}\right)$ (Zhao et al., 2020c), thus proving that the cross-flow can be used for harvesting microalgae at current velocity $(0.0025 \mathrm{~m} / \mathrm{s}$ and the corresponding shear rate of $0.94 \mathrm{~s}^{-1}$ ) without cell damage.

\subsection{Reversible and irreversible fouling}

\subsubsection{Membrane permeance decline}

Fig. 6 shows the membrane permeances during the filtrations of three different feeds (UMS, FSS and FOS) using flat and patterned membranes at 4 different cross-flow velocities $(0.0025,0.005,0.01$ and $0.0125 \mathrm{~m} / \mathrm{s}$ ). An intermediate cleaning procedure was performed in each cycle to remove the reversible fouling and recover permeance (referred to "recovered permeance"). For both membranes, the permeance rapidly decreased during the initial filtration, and a cake layer is formed by deposition of EOM and microalgal cells, which serves as a secondary filtration layer (Zhao et al., 2020b). Reversible fouling can be removed by "relaxation", implementing a lowered TMP, while irreversible fouling can only be removed by chemical cleaning (Bilad et al., 2012). After relaxation, the membrane permeance significantly increased for all microalgal suspension (i.e. UMS, FSS and FOS). However, the recovered permeance decreased with filtration time, indicating increased irreversible fouling, in accordance with previous studies (Elcik et al., 2016; Zhang et al., 2019). The membrane permeances were in line with the results in 3.2. An unexpected result was found for the patterned membrane in FOS: after $1.5 \mathrm{~h}$ filtration, only at a velocity of $0.0025 \mathrm{~m} / \mathrm{s}$ the highest membrane permeance was obtained, while the highest recovered permeance was always obtained at $0.015 \mathrm{~m} / \mathrm{s}$ (Fig. 6f). Possibly, bigger particles led to a higher membrane permeance when using FOS as feed (see 3.2).

\subsubsection{Membrane fouling resistance}

Fig. 7 shows the fouling reversibility while filtering UMS, FSS and FOS using flat and patterned membranes at four different velocities. All feeds caused both reversible and irreversible fouling. During the filtration cycles, the irreversible fouling increased, while 
(a)

Flat membranes

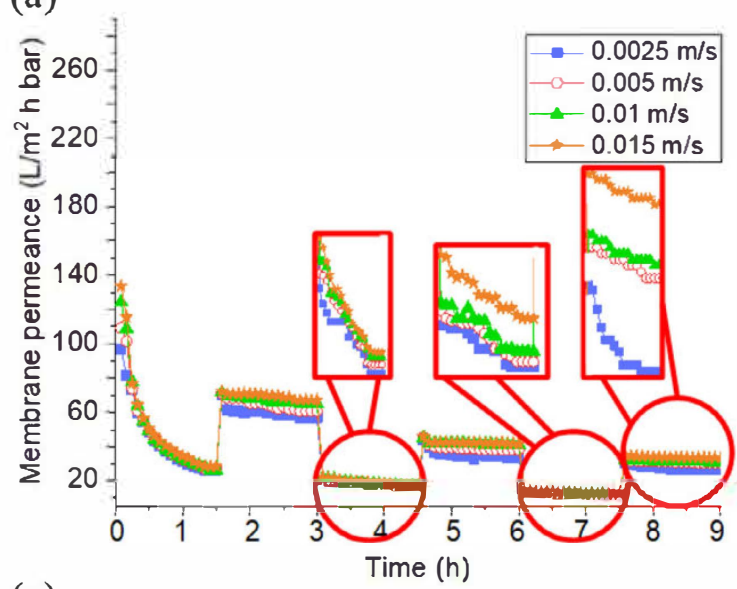

(c)

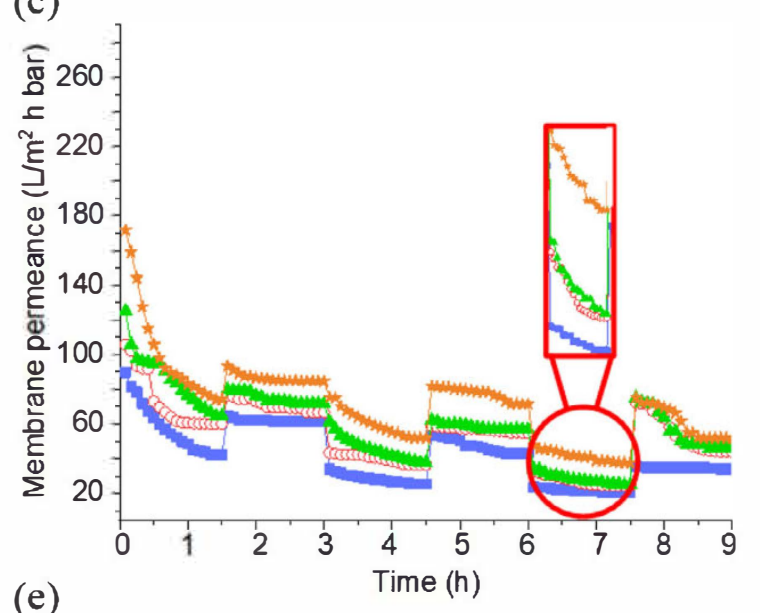

(e)

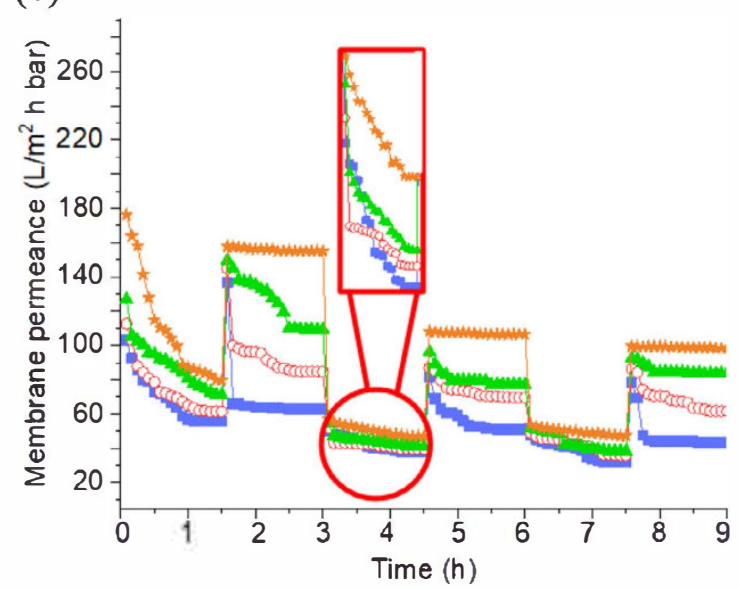

Patterned membranes

(b)

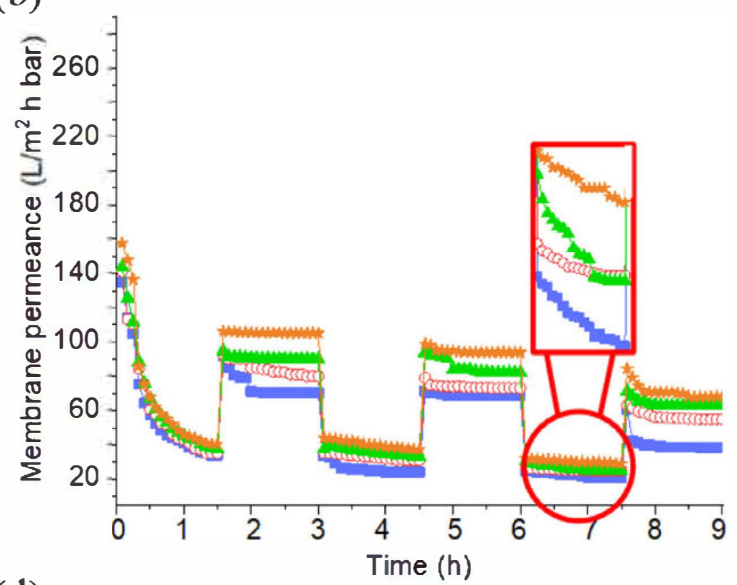

(d)

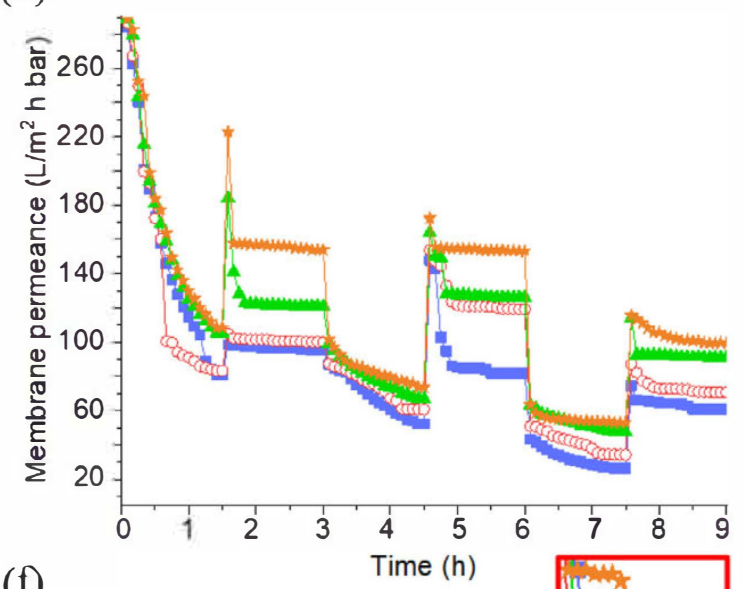

(f)

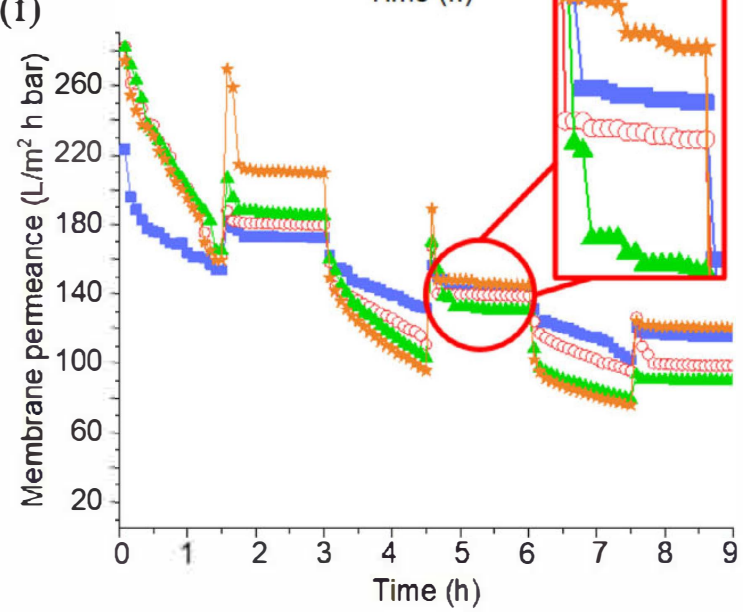

Fig. 6. Membrane permeance decline in (a and b) UMS, (c and d) FSS and (e and f) FOS with an intermediate cleaning procedure (i.e. relaxation by implementing a lowered TMP) in a cross-flow system.

the reversible fouling decreased, proving that the increased irreversible fouling led to a decreased recovered permeance. For flat membranes (Figs. 7a-7c), the irreversible fouling decreased with increasing flocculant dosage and cross-flow velocity. It has been reported that EOM plays an important role in irreversible fouling (Zhang et al., 2019), which can not only form a dense layer but also can agglomerate microalgal cells on the membrane surface. Flocculation can significantly reduce the EOM content, thus reducing irreversible fouling (Zhao et al., 2020b). The irreversible and total fouling on patterned membranes were significantly lower than on flat membranes, confirming that patterned membranes have a higher fouling resistance. Previous studies showed an enhanced shear on the pattern apexes, and vortices in the valleys (Lee et al., 2013; Zhao et al., 2020a). The enhanced shear can prevent microalgae from attaching on the apexes (Lee et al., 2013), while the extra mixing effect created by the vortices can mitigate microalgae deposition in the valley (Zhao et al., 2020a). Both factors resulted in the final high membrane permeances and fouling resistances. The same trend was also found in UMS and FSS. However, the highest irreversible fouling was found at velocities of 0.005 and $0.01 \mathrm{~m} / \mathrm{s}$ in 
Flat membranes

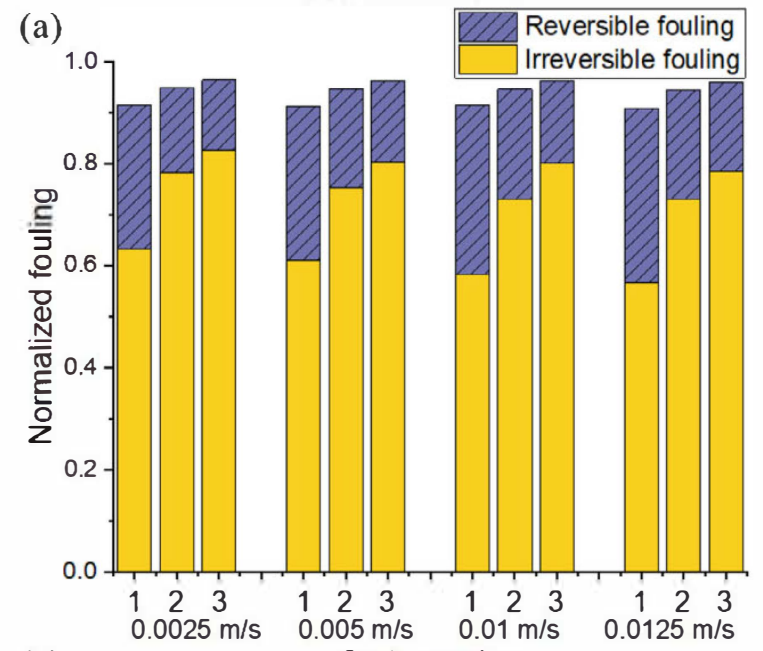

(c)
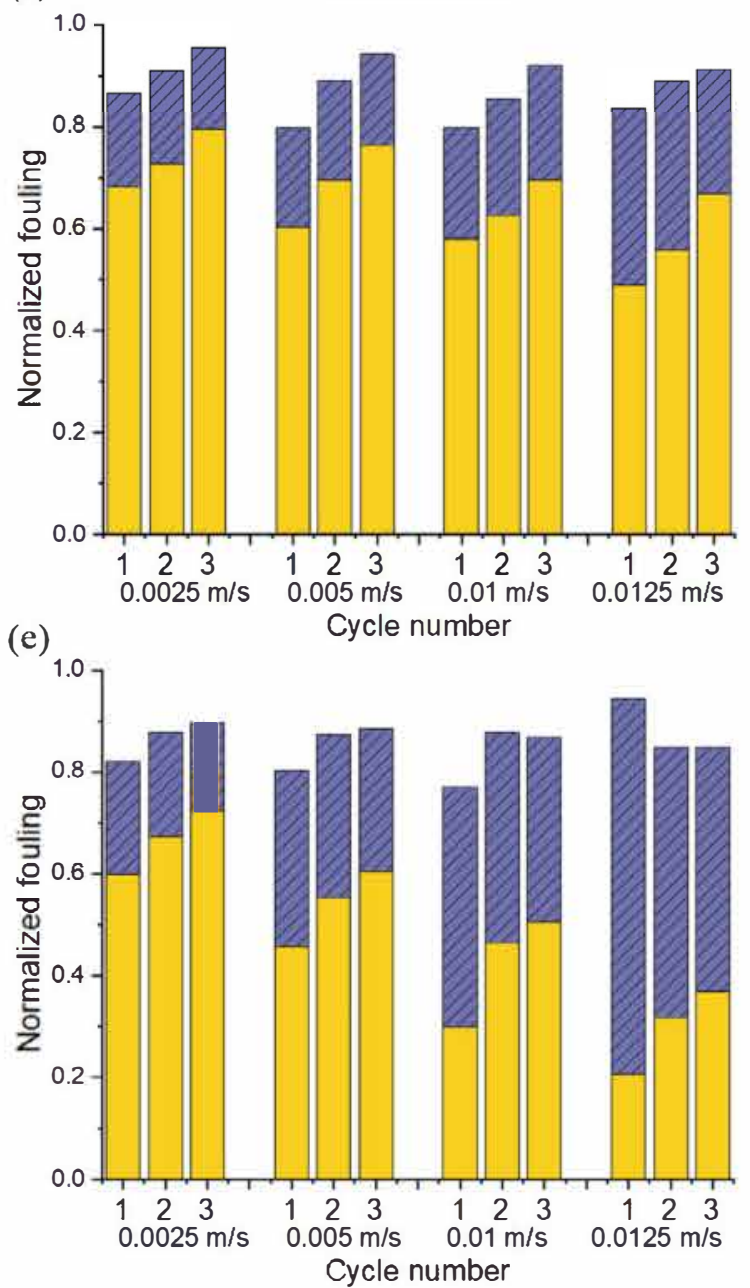

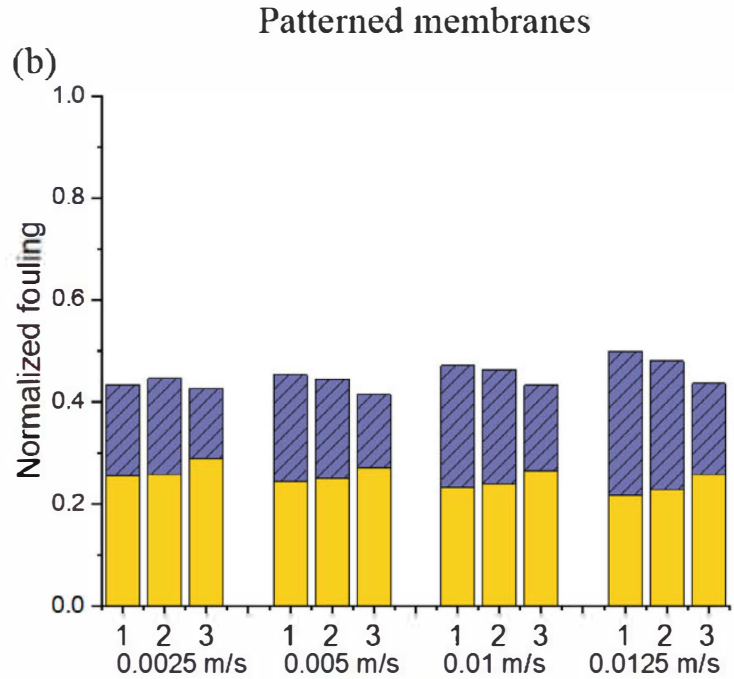

(d)
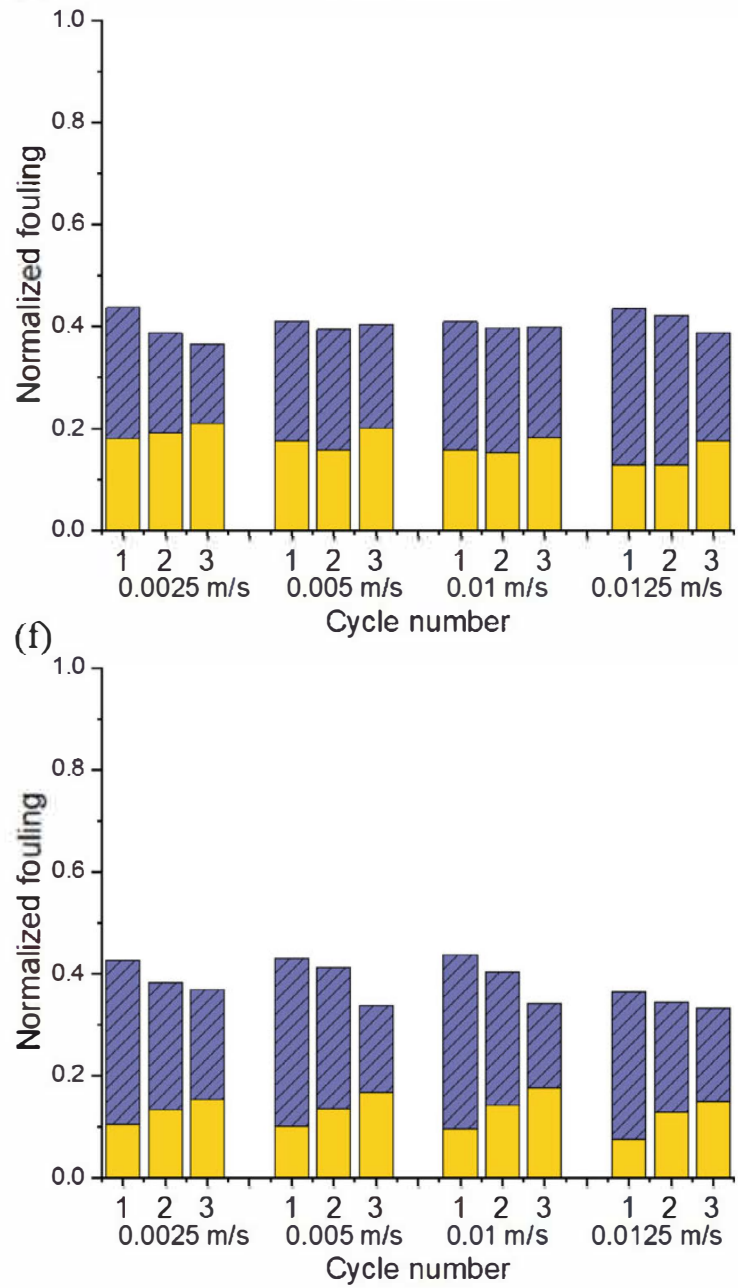

Fig. 7. Membrane fouling resistance in 3 cycles (1, 2, 3 refer to cycle membranes) using (a and b) UMS, (c and d) FSS and (e and f) FOS as feeds in a cross-flow system.

FOS. This is in line with the results in 3.2 where the lowest membrane permeances were obtained at those velocities. Besides, a velocity of $0.0025 \mathrm{~m} / \mathrm{s}$ only gave the highest irreversible fouling in the first cycle and showed relatively low irreversible fouling in the next two cycles, again proving the anti-fouling synergy between patterned membrane and flocculation at low cross-flow velocity.
This becomes even more clear when comparing with a previous study, in which the membrane permeance of a polyvinyl chloride membrane after cleaning was $86 \mathrm{~L} / \mathrm{m}^{2}$ h bar at a cross-flow velocity of $0.13 \mathrm{~m} / \mathrm{s}$ (Zhang et al., 2019). In current study, a significantly higher membrane permeance of $110 \mathrm{~L} / \mathrm{m}^{2} \mathrm{~h}$ bar was obtained by combining flocculation and membrane patterning at a 

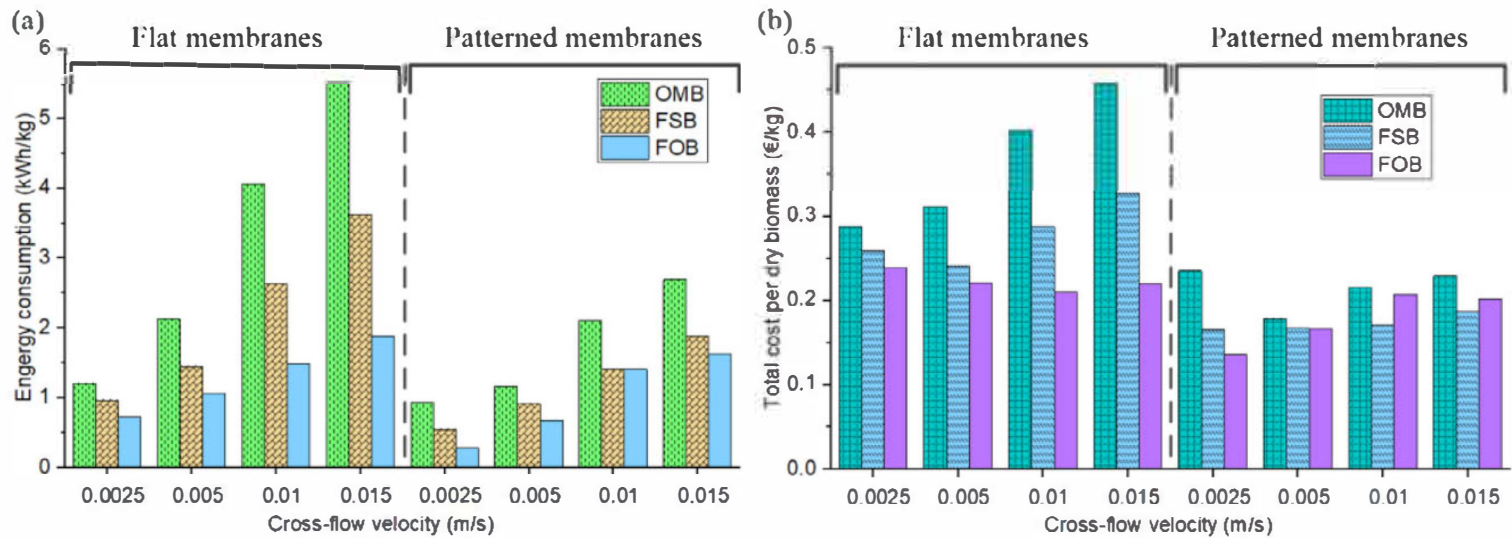

Fig. 8. Calculated (a) energy consumption and (b) total cost per dry biomass in a full-scale harvesting system under different chitosan concentrations (i.e. UMS, FSS and FOS) at different cross-flow velocities $(0.0025,0.005,0.01$ and $0.015 \mathrm{~m} / \mathrm{s})$.

very low velocity of $0.0025 \mathrm{~m} / \mathrm{s}$ only (i.e. strongly reduced energy requirement).

\subsection{Economical analysis of microalgae harvesting using patterned membranes}

\subsubsection{Cost analysis}

3.4.1.1. General. A cost analysis for the application of membrane technology in large-scale microalgae harvesting was estimated for a scale of $600 \mathrm{~m}^{2}$ membrane area to compare the results with a full-scale unit in a previous study (Wang et al., 2019), with a microalgal concentration of $0.81 \mathrm{~g} / \mathrm{L}$ under an operational pressure of 1.5 bar. Current economic analysis is based on a stable membrane permeance without cleaning, since very low frequencies of cleaning are exactly the main advantage of the combination of patterned membranes and flocculation. The cost of water and possible chemicals during cleaning was thus not included in the economic analysis. This economic analysis is based on Belgium prices.

The effects of cross-flow velocity, chitosan concentration (i.e. $0 \mathrm{mg} / \mathrm{L}$ for UMS, $2 \mathrm{mg} / \mathrm{L}$ for FSS and $5 \mathrm{mg} / \mathrm{L}$ for FOS) and membrane type (i.e. flat and patterned membranes) on the energy consumption of the cross-flow system (including the energy consumption of pumps, stirrer and compressed air) are shown in Fig. 8a. The energy consumption logically increased with increasing crossflow velocity due to extra pumping. Both increasing cross-flow velocity and chitosan concentration increased membrane permeance, and the membrane permeance is strongly related to the energy consumption (Eq. (10)), showing that a higher membrane permeance leads to a lower energy consumption under unchanged surrounding conditions. The current results showed that the high membrane permeance induced by high cross-flow velocity oppositely gave a higher energy consumption per $\mathrm{kg}$ of harvested microalgae. A similar result was also found in a previous study where an increasing vibration frequency increased membrane permeance, but also energy consumption (Zhao et al., 2020a). Importantly, the energy consumption using patterned membranes was significantly lower than using flat membranes.

3.4.1.2. Energy calculation. Centrifugation has been widely used in microalgal industry due to its high harvesting efficiency (Zhao et al., 2020a) with an energy consumption of $9.8 \mathrm{kWh} / \mathrm{kg}$ $\left(8 \mathrm{kWh} / \mathrm{m}^{3}\right)$ to achieve $>90 \%$ harvesting efficiency (Bilad et al., 2012). A previous study that combined chitosan flocculation with membrane filtration resulted in a very low energy consumption of $0.07 \mathrm{kWh} / \mathrm{kg}$ (Fasaei et al., 2018). The use of a peristaltic pump at lab-scale (unfortunately impossible to upscale properly) might be the reason for this extremely low energy consump- tion. Besides, energy consumptions of stirring and compressed air were not included in that study. A very low energy consumption $(0.28 \mathrm{kWh} / \mathrm{kg})$ was found when using patterned membranes in FOS (Fig. 8a), because a very high membrane permeance $\left(110 \mathrm{~L} / \mathrm{m}^{2} \mathrm{~h}\right.$ bar) was achieved at a low cross-flow velocity $(0.0025 \mathrm{~m} / \mathrm{s})$. The current result showed an important improvement compared to other studies for microalgae harvesting using membrane technology at full-scale or pilot-scale, such as harvesting Scenedesmus acuminatus (S. acuminatus) $(0.59 \mathrm{kWh} / \mathrm{kg})$ and $C$. minutissima $(1.27 \mathrm{kWh} / \mathrm{kg}$ ) in cross-flow system (Gerardo et al., 2015; Wang et al., 2019), and harvesting C. vulgaris (0.64 kWh $/ \mathrm{kg}$ ) and Phaeodactylum tricornutum $(0.98 \mathrm{kWh} / \mathrm{kg})$ using submerged microfiltration membranes (Bilad et al., 2012). The energy consumption results thus again confirm the excellent synergy between membrane patterning and flocculation.

3.4.1.3. Cost calculation. Capital and labor costs are included in Table S2 and in Fig. 8b in a full-scale harvesting system, including capital, labor, energy and reagent (chitosan and $\mathrm{HCl}$ ) costs. The lowest total cost $(0.16 € / \mathrm{kg})$ was found when using patterned membranes in FOS at a cross-flow velocity of $0.0025 \mathrm{~m} / \mathrm{s}$. Normally, the total harvesting cost using centrifugation is around 1.5 $€ / \mathrm{kg}$ (Fasaei et al., 2018). A previous study showed that the total harvesting cost of $S$. acuminatus in a full-scale cross-flow system was $0.26 € / \mathrm{kg}$ (Wang et al., 2019), and $0.297 € / \mathrm{kg}$ when combining membrane filtration with chitosan flocculation (Fasaei et al., 2018). A big decline by more than $40 \%$ was thus achieved in current study when combining patterned membranes with flocculation.

\subsubsection{Sensitivity analysis}

Fig. 9 shows the sensitivity of the total harvesting cost (combination of patterned membrane filtration and flocculation under chitosan concentration of $5 \mathrm{mg} / \mathrm{L}$ at a cross-flow velocity of $0.0025 \mathrm{~m} / \mathrm{s}$ ).

A positive sensitivity coefficient means that the total harvesting cost increases/decreases with increasing/decreasing parameter value. A higher absolute value of a sensitivity coefficient shows that the corresponding parameter plays a bigger role on the total harvesting cost (Ketheesan and Nirmalakhandan, 2013). According to Fig. 9, only membrane life showed a negative correlation, as the membrane is more efficiently used with a longer operational time. Similar results were also found in previous studies (Fasaei et al., 2018; Wang et al., 2019). Decreasing the membrane life time can significantly increase the total harvesting costs at the estimated, non-optimized membrane costs. Fouling is always one of the biggest problems in membrane filtration in general, which directly influences the filtration performance as well as 


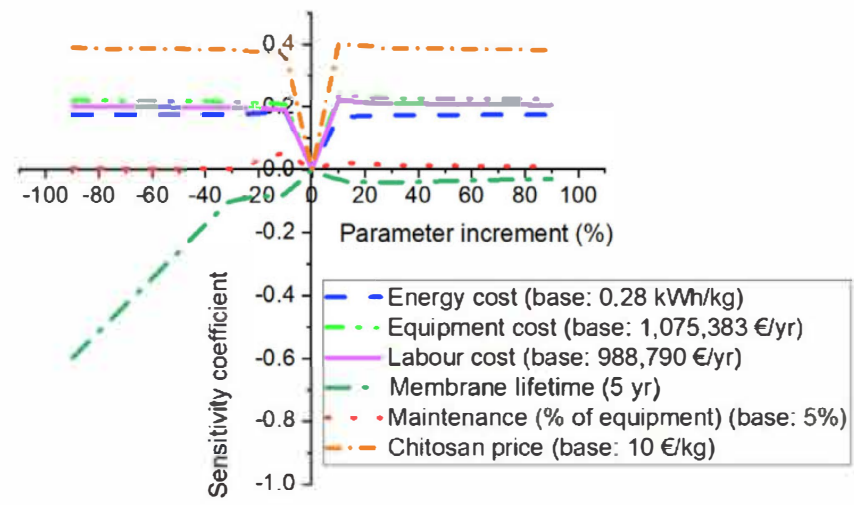

Fig. 9. Sensitivity analysis of selected parameters on the total harvesting cost using patterned membrane filtration in FOS at a cross-flow velocity of $0.0025 \mathrm{~m} / \mathrm{s}$.

the membrane life time through the implemented cleaning cycles (Bilad et al., 2012; Zhao et al., 2020a). In current study, patterned membranes showed a greater antifouling capacity than flat membranes especially when combined with flocculation, giving a longer lifetime and therefore decreasing the total harvesting cost.

Chitosan price had the highest sensitivity coefficient. In other studies, the energy cost gave the highest contribution to the total harvesting cost (Pahl et al., 2013; Wang et al., 2019), because a high cross-flow velocity was required ( $>0.3 \mathrm{~m} / \mathrm{s}$ ) to achieve a sufficiently high membrane permeance (Elcik et al., 2016; Wang et al., 2019; Zhang et al., 2019). However, in current study, a very low cross-flow velocity $(0.0025 \mathrm{~m} / \mathrm{s})$ can already achieve a very high membrane permeance $\left(110 \mathrm{~L} / \mathrm{m}^{2} \mathrm{~h}\right.$ bar) when combined with flocculation, thus strongly decreasing the impact of energy cost.

\section{Conclusions}

A PEG concentrations of $28 \mathrm{w} \%$ was found to optimally prepare wave-patterned membranes with the highest average CWP $\left(900 \pm 22 \mathrm{~L} / \mathrm{m}^{2} \mathrm{~h}\right.$ bar) and microalgal suspension permeance $\left(590 \pm 17 \mathrm{~L} / \mathrm{m}^{2} \mathrm{~h}\right.$ bar) for Dictyosphaerium sp.. The flat and patterned membranes prepared by the optimized casting solution could all achieve the highest $\mathrm{CP}$ of 2.5 bar.

Membrane permeance and irreversible fouling gradually decreased with increasing cross-flow velocity and chitosan dosage, while patterned membranes combined with chitosan flocculation at optimized conditions $(5 \mathrm{mg} / \mathrm{L})$ gave the highest stable membrane permeance and the lowest irreversible fouling at a very low velocity of $0.0025 \mathrm{~m} / \mathrm{s}$.

The energy consumption and total harvesting cost were simulated for a full-scale microalgal harvesting plant, showing an extremely low energy consumption of $0.28 \mathrm{kWh} / \mathrm{kg}$ and a competitive total harvesting cost of $0.16 € / \mathrm{kg}$. The sensitivity analysis showed that chitosan price and labor cost contributed most to the total harvesting cost, while the energy cost and maintenance contributed least. Membrane life also showed a significant impact. Patterned membrane filtration combined with flocculation showed strong antifouling properties which decreases the need for cleaning and might potentially increase membrane lifetimes significantly. It can thus be considered as an important strategy to enhance membrane lifetime and significantly decrease harvesting cost and energy inputs.

\section{Declaration of Competing Interest}

The authors declare that they have no known competing financial interests or personal relationships that could have appeared to influence the work reported in this paper.

\section{Acknowledgements}

Zhenyu Zhao acknowledges the China Scholarship Council for financial support.

\section{Supplementary materials}

Supplementary material associated with this article can be found, in the online version, at doi:10.1016/j.watres.2021.117181.

\section{Reference}

Balti, R., Le Balc'h, R., Brodu, N., Gilbert, M., Le Gouic, B., Le Gall, S., Sinquin, C., Massé, A, 2018. Concentration and purification of Porphyridium cruentum exopolysaccharides by membrane filtration at various cross-flow velocities. Process Biochem. 74, 175-184.

Bilad, M.R., Arafat, H.A., Vankelecom, I.F.J, 2014. Membrane technology in microalgae cultivation and harvesting: a review. Biotechnol. Adv. 32 (7), 1283-1300.

Bilad, M.R., Azizo, A.S., Wirzal, M.D.H., Jia Jia, L., Putra, Z.A., Nordin, N.A.H.M., Mavukkandy, M.O., Jasni, M.J.F., Yusoff, A.R.M, 2018. Tackling membrane fouling in microalgae filtration using nylon 6,6 nanofiber membrane. J. Environ. Manage. 223, 23-28.

Bilad, M.R., Discart, V., Vandamme, D., Foubert, I., Muylaert, K., Vankelecom, I.F., 2013. Harvesting microalgal biomass using a magnetically induced membrane vibration (MMV) system: filtration performance and energy consumption. Bioresour. Technol. 138, 329-338.

Bilad, M.R., Marbelia, L., Laine, C., Vankelecom, I.FJ, 2015. A PVC-silica mixed-matrix membrane (MMM) as novel type of membrane bioreactor (MBR) membrane. J. Memb. Sci. 493, 19-27.

Bilad, M.R., Vandamme, D., Foubert, I., Muylaert, K., Vankelecom, I.F.J, 2012. Harvesting microalgal biomass using submerged microfiltration membranes. Bioresour. Technol. 111, 343-352.

Blockx, J., Verfaillie, A., Thielemans, W., Muylaert, K., 2018. Unravelling the mechanism of chitosan-driven flocculation of microalgae in seawater as a function of pH. ACS Sustain Chem Eng 6 (9), 11273-11279.

Chang, Y.-.R., Lee, D.-.J., 2012. Coagulation-membrane filtration of Chlorella vulgaris at different growth phases. Drying Technol. 30 (11-12), 1317-1322.

Chen, C., Zhao, Z., Ma, S., Rasool, M.A., Wang, L., Zhang, J., 2020. Optimization of ultrasonic-assisted extraction, refinement and characterization of water-soluble polysaccharide from Dictyosphaerium sp. and evaluation of antioxidant activity in vitro. J. Food Meas. Characterization 14 (2), 963-977.

Discart, V., Bilad, M.R., Moorkens, R., Arafat, H., Vankelecom, I.F.J, 2015. Decreasing membrane fouling during Chlorella vulgaris broth filtration via membrane development and coagulant assisted filtration. Algal Res. 9, 55-64.

Elcik, H., Cakmakci, M., Ozkaya, B., 2016. The fouling effects of microalgal cells on crossflow membrane filtration. J. Memb. Sci. 499, 116-125.

Fasaei, F., Bitter, J.H., Slegers, P.M., van Boxtel, A.J.B., 2018. Techno-economic evaluation of microalgae harvesting and dewatering systems. Algal Res. 31, 347-362.

Gerardo, M.L., Zanain, M.A., Lovitt, R.W., 2015. Pilot-scale cross-flow microfiltration of Chlorella minutissima: a theoretical assessment of the operational parameters on energy consumption. Chem. Eng. J. 280, 505-513.

Gonçalves, B.R., Machado, A.E.H., Trovó, A.G, 2017. Treatment of a biodiesel effluent by coupling coagulation-flocculation, membrane filtration and Fenton reactions. J. Clean. Prod. 142, 1918-1921.

Hołda, A.K., Aernouts, B., Saeys, W., Vankelecom, I.F.J, 2013. Study of polymer concentration and evaporation time as phase inversion parameters for polysulfone-based SRNF membranes. J. Memb. Sci. 442, 196-205.

Hołda, A.K., Vankelecom, I.F.J, 2014. Integrally skinned PSf-based SRNF-membranes prepared via phase inversion-Part A: influence of high molecular weight additives. J. Memb. Sci, 450, 512-521.

Hołda, A.K., Vankelecom, I.F.J, 2015. Understanding and guiding the phase inversion process for synthesis of solvent resistant nanofiltration membranes. J. Appl. Polym. Sci. 132 (27).

Huang, R. Liu, Z., Yan, B., Li, Y., Li, H., Liu, D., Wang, P., Cui, F., Shi, W., 2020. Layer-by-layer assembly of high negatively charged polycarbonate membranes with robust antifouling property for microalgae harvesting. J. Memb. Sci. 595, 117488.

Ilyas, A., Mertens, M., Oyaert, S., Vankelecom, I.F.J, 2020. Synthesis of patterned PVDF ultrafiltration membranes: spray-modified non-solvent induced phase separation. J. Memb. Sci. 612, 118383.

Kang, S.-.T., Subramani, A., Hoek, E.M.V., Deshusses, M.A., Matsumoto, M.R, 2004. Direct observation of biofouling in cross-flow microfiltration: mechanisms of deposition and release. J. Memb. Sci. 244 (1), 151-165.

Ketheesan, B., Nirmalakhandan, N., 2013. Modeling microalgal growth in an airliftdriven raceway reactor. Bioresour. Technol. 136, 689-696.

Lee, D.-J., Liao, G.-.Y, Chang, Y.-.R., Chang, J.-.S., 2012a. Chitosan coagulation-membrane filtration of Chlorella vulgaris. Int J Hydrogen Energy 37 (20), 15643-15647,

Lee, D.-.J., Liao, G.-.Y., Chang, Y.-.R., Chang, J.-S., 2012b. Coagulation-membrane filtration of Chlorella vulgaris. Bioresour. Technol. 108, 184-189.

Lee, Y.K., Won, Y.-.J., Yoo, J.H., Ahn, K.H., Lee, C.-.H., 2013. Flow analysis and fouling on the patterned membrane surface. J Memb Sci 427, 320-325.

Lu, D., Jia, B., Xu, S., Wang, P., Song, D., Lin, R., Sun, Y., Ma, J., 2020. Role of pre-coag ulation in ultralow pressure membrane system for Microcystis aeruginosa-laden 
water treatment: membrane fouling potential and mechanism. Sci. Total Environ. 710,136340

Ma, Y., Shi, F., Ma, J., Wu, M., Zhang, J., Gao, C., 2011. Effect of PEG additive on the morphology and performance of polysulfone ultrafiltration membranes. Desalination $272(1-3), 51-58$.

Marbelia, L., Ilyas, A., Dierick, M., Qian, J., Achille, C., Ameloot, R., Vankelecom, I.F.J, 2020. Preparation of patterned flat-sheet membranes using a modified phase inversion process and advanced casting knife construction techniques. J. Memb. Sci. 597, 117621.

Mo, W., Soh, L., Werber, J.R., Elimelech, M., Zimmerman, J.B., 2015. Application of membrane dewatering for algal biofuel. Algal Res. 11, 1-12.

Nasirian, D., Salahshoori, I., Sadeghi, M., Rashidi, N., Hassanzadeganroudsari, M., 2019. Investigation of the gas permeability properties from polysulfone/polyethylene glycol composite membrane. Polym. Bull.

Pahl, S.L., Lee, A.K., Kalaitzidis, T., Ashman, P.J., Sathe, S. and Lewis, D.M. (2013) Algae for Biofuels and Energy. Borowitzka, M.A. and Moheimani, N.R. (eds), pp. 165185, Springer Netherlands, Dordrecht.

Vandamme, D., Foubert, I., Fraeye, I., Meesschaert, B., Muylaert, K., 2012a. Flocculation of Chlorella vulgaris induced by high $\mathrm{pH}$ : role of magnesium and calcium and practical implications. Bioresour. Technol. 105, 114-119.

Vandamme, D., Foubert, I., Fraeye, I., Muylaert, K., 2012b. Influence of organic matter generated by Chlorella vulgaris on five different modes of flocculation. Bioresour. Technol. 124, 508-511.

Vandamme, D., Foubert, I., Muylaert, K., 2013. Flocculation as a low-cost method for harvesting microalgae for bulk biomass production. Trends Biotechnol. 31 (4) 233-239.

Wan, C. Alam, M.A., Zhao, X.-.Q., Zhang, X.-.Y., Guo, S.-.L., Ho, S.-.H., Chang, J.-.S Bai, F.-.W., 2015. Current progress and future prospect of microalgal biomass harvest using various flocculation technologies. Bioresour. Technol. 184, 251-257.

Wang, L., Pan, B., Gao, Y., Li, C., Ye, J., Yang, L., Chen, Y., Hu, Q., Zhang, X., 2019. Efficient membrane microalgal harvesting: pilot-scale performance and techno-economic analysis. J. Clean. Prod. 218, 83-95.
Wicaksana, F., Fane, A.G., Pongpairoj, P., Field, R., 2012. Microfiltration of algae (Chlorella sorokiniana): critical flux, fouling and transmission. J. Memb. Sci. 387-388, 83-92.

Xu, Y., Purton, S., Baganz, F., 2013. Chitosan flocculation to aid the harvesting of the microalga Chlorella sorokiniana. Bioresour. Technol. 129, 296-301.

Zhang, S., Gao, Y., Liu, Q., Ye, J., Hu, Q., Zhang, X., 2019. Harvesting of Isochrysis zhanjiangensis using ultrafiltration: changes in the contribution ratios of cells and algogenic organic matter to membrane fouling under different cross-flow velocities. Algal Res. 41, 101567.

Zhao, Z., Ilyas, A., Muylaert, K., Vankelecom, I.F.J, 2020a. Optimization of patterned polysulfone membranes for microalgae harvesting. Bioresour. Technol. 309, 123367.

Zhao, Z., Li, Y., Muylaert, K., Vankelecom, I.F.J, 2020b. Synergy between membrane filtration and flocculation for harvesting microalgae. Sep. Purif. Technol. 240, 116603.

Zhao, Z., Ma, S., Li, A., Liu, P., Wang, M., 2016. Effects of trophic modes, carbon sources, and salinity on the cell growth and lipid accumulation of tropic ocean oilgae strain Desmodesmus sp. WC08. Appl. Biochem. Biotechnol. 180 (3), 452-463.

Zhao, Z., Mertens, M., Li, Y., Muylaert, K., Vankelecom, I.F.J., 2020c. A highly efficient and energy-saving magnetically induced membrane vibration system for harvesting microalgae. Bioresour. Technol. 300, 122688.

Zhao, Z., Muylaert, K., Szymczyk, A., Vankelecom, I.F.J, 2021. Harvesting microalga biomass using negatively charged polysulfone patterned membranes: influence of pattern shapes and mechanism of fouling mitigation. Water Res. 188, 116530

Zhao, Z., Rasool, M.A., Chen, C., Ma, S., Wang, L., Huang, G., 2020d. Identification and screening of multiple tropical microalgal strains for antioxidant activity in vitro. Food Biosci., 100649 